\title{
The endoscopic findings of the upper gastrointestinal tract in patients with Crohn's disease
}

\author{
Yoshiki Nomura $^{1} \cdot$ Kentaro Moriichi $^{1} \cdot$ Mikihiro Fujiya $^{1} \cdot$ Toshikatsu Okumura $^{1}$
}

Received: 23 May 2017/ Accepted: 8 June 2017/Published online: 10 July 2017

(C) Japanese Society of Gastroenterology 2017

\begin{abstract}
Crohn's disease (CD) is a type of chronic inflammatory bowel disease (IBD) associated with ulceration, and the main foci of the inflammation in CD patients are typically the terminal ileum and colon. However, in the upper gastrointestinal tract (GIT), including the esophagus, stomach and duodenum, inflammatory lesions are also detected as well, with a relatively high frequency (30-75\%). Recent advances in imaging modalities, including endoscopy, have aided in the diagnosis of CD. Various lesions, including aphtha, erosion, ulcers, bamboojoint-like appearance and notch-like appearance, are detected in the upper GI of CD patients. Of these lesions, the bamboo-joint-like appearance in the gastric cardiac region and notch-like appearance in the second portion of the duodenum are highly specific for $\mathrm{CD}$, regardless of the disease activity at other sites. These two findings, particularly a bamboo-joint-like appearance, have therefore been considered as potential biomarkers for $\mathrm{CD}$. Although proton pump inhibitors (PPIs) are administered as an initial treatment for upper GIT lesions of $\mathrm{CD}$, the efficacy of this treatment remains controversial. The administration of mesalazine, steroids, immunosuppressant and biologic agents is expected to be effective for treating such lesions.
\end{abstract}

Keywords Crohn's disease (CD) - Upper gastrointestinal tract (GIT) · Bamboo-joint-like appearance $\cdot$ Non-caseating granulomas

Kentaro Moriichi

morimori@asahikawa-med.ac.jp

1 Division of Gastroenterology and Hematology/Oncology, Department of Medicine, Asahikawa Medical University, 2-1-1-1 Midorigaoka-Higashi, Asahikawa, Hokkaido 078-8510, Japan

\section{Introduction}

Crohn's disease (CD) is a chronic inflammatory bowel disease (IBD) associated with ulceration. CD patients experience repeated episodes of clinical remission and relapse. Endoscopic examination plays an important role in the diagnosis of $\mathrm{CD}$, and endoscopic findings, such as longitudinal ulcers and a cobblestone appearance, are typical in $\mathrm{CD}$ patients [1-4]. However, the cobblestone appearance is not often observed in CD patients [5]. In addition, longitudinal ulcers can be observed in patients with ischemic colitis, Behcet's disease and collagenous colitis as well as CD. Non-caseating granulomas are a typical histologic finding of CD. Thus, the detection of granulomas from biopsy specimens makes the diagnosis more accurate. Granuloma is reported to be detected in $40-60 \%$ of surgical specimens and $15-36 \%$ of biopsy specimens [6]. The main foci of inflammation in $C D$ patients are typically the terminal ileum and colon; however, the entire gastrointestinal tract, from the oral cavity to the anus, can be involved. In addition to the lower gastrointestinal tract (GIT), the upper GIT (including the esophagus, stomach and duodenum) also shows inflammatory lesions; thus, esophagogastroduodenoscopy (EGD) is thought to be essential for detecting the characteristic findings and making a differential diagnosis in CD patients. The upper GIT lesions of CD were first reported by Gottlieb in 1937 [7]. Although several reports of upper GIT lesions in $\mathrm{CD}$ patients were subsequently reported, they were reported to be rare $(2-3 \%)[8,9]$. Since the 1980 s, endoscopic technology and diagnostic accuracy have improved and upper GIT lesions can be detected by EGD; thus, numerous reports have been published on the diagnostic imaging of upper gastrointestinal lesions. The results have revealed that the frequency of upper GIT lesions in 
Table 1 Frequencies of upper gastrointestinal tract lesions in Crohn's disease

\begin{tabular}{cll}
\hline & Lesions & $\begin{array}{l}\text { Frequencies of upper } \\
\text { GIT lesions (\%) }\end{array}$ \\
\hline $\begin{array}{lll}\text { Esophageal } \\
\text { lesions }\end{array}$ & $\begin{array}{l}\text { Aphtha } \\
\text { Erosion } \\
\text { Glcer }\end{array}$ & $0.2-6$ \\
& Aphtha & \\
& Erosion & $24-73$ \\
& Ulcer & \\
& Bamboo-joint-like & \\
& appearance & \\
Duodenal & Aphtha & $21-32.1$ \\
lesions & Erosion & \\
& Ulcer & \\
& Notch-like appearance & \\
& Protruding lesions & \\
\hline
\end{tabular}

CD patients was never low (30-75\%) (Table 1) [9-17]. The present review describes the typical findings, which are useful for the diagnosis of $\mathrm{CD}$, in each part of the upper GIT.

Fig. 1 Esophageal erosion showed a longitudinal tendency in Crohn's disease (a distant view of the lesions $\mathbf{a}$; a closerange view of the lesions $\mathbf{b}$; an indigo carmine chromoendoscopic finding $\mathbf{c}$ )

\section{Esophageal lesions}

According to previous reports, the frequency of esophageal lesions in CD patients ranges from 0.2 to $6 \%$ [18-21]. They are detected less frequently than gastric or duodenal lesions. In mild cases, the endoscopic findings of esophageal lesions show scattered erosion. In moderate cases, aphthoid lesions and ulceration are intermingled, and the lesions frequently show a longitudinal tendency (Fig. 1ac). In severe cases, longitudinally aligned ulcers, a cobblestone appearance and fistulas are observed [20-23]. Decker et al. reported that the incidences of esophageal lesions, including ulcer, erosion, stricture and fistula, were $85,40,20$ and 5\%, respectively [20]. De Felice et al. reported similar results, noting that the incidence of superficial ulceration, erosion, deep ulceration, pseudopolyps, stricture and fistula were 58, 50, 13, 4, 17 and $8 \%$, respectively [23]. However, these lesions are not specific to $\mathrm{CD}$ and must therefore be distinguished from other diseases, such as gastro-esophageal reflux disease, eosinophilic esophagitis, drug-induced esophagitis, viral and fungal infection, tuberculosis, vasculitis and
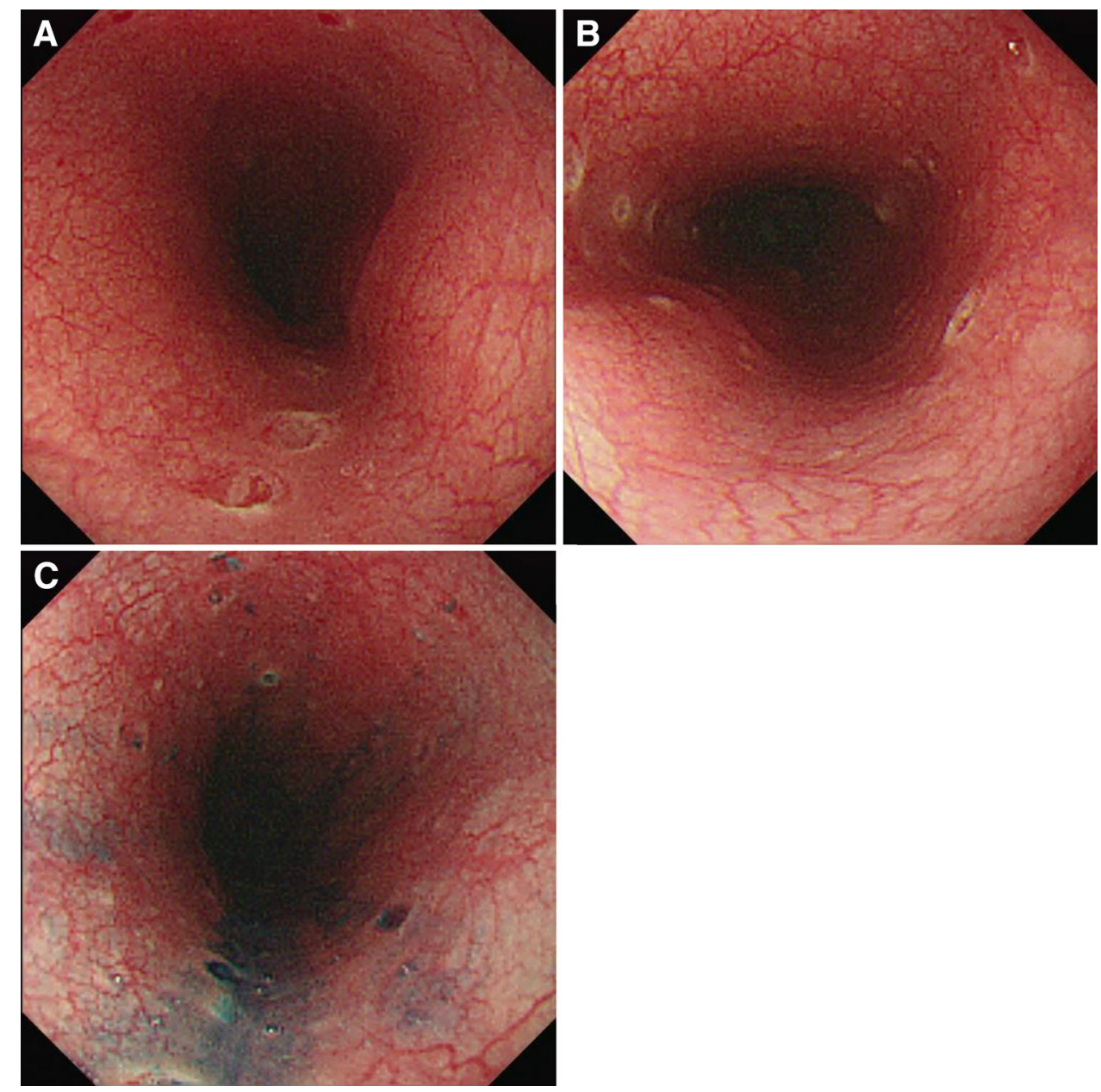
Table 2 Granuloma detection rate in upper gastrointestinal tract lesions in Crohn's disease

\begin{tabular}{ll}
\hline & Granuloma detection rates $(\%)$ \\
\hline Esophageal lesions & $<25$ \\
Gastric lesions & $7-48.7$ \\
Bamboo-joint-like appearance & $14.3-45.5$ \\
Duodenal lesions & $0-49$ \\
\hline
\end{tabular}

malignancies [24]. Granuloma is detected in $<25 \%$ of esophageal biopsy specimens (Table 2) [22, 25, 26]; thus, even in cases in which granulomas is not detected, it is important to treat the case as $\mathrm{CD}$, because the diagnosis of $\mathrm{CD}$ can be made endoscopically.

There is no established therapeutic strategy for esophageal lesions in CD patients. The European Crohn's and Colitis Organization (ECCO) proposes the administration of proton pump inhibitors (PPIs) as for the treatment of esophageal lesions in CD patients [27]. However, PPI monotherapy is not suitable for maintenance therapy in patients with esophageal lesions; thus, the additional administration of an immunosuppressant should also be considered [24]. Other drug therapies, including prednisone, topical budesonide and biologic agents, are also known to be effective. The administration of these drugs is considered based on the disease severity and has been shown to improve esophageal lesions. Dilatation therapy is also effective for esophageal stenosis [23]. The main adverse events of this therapy are esophageal perforation and bleeding, and the treatment is considered to be less of a burden on the patient in comparison to surgery. Surgery is an option for patients with intractable stricture, fistula or abscess [28]. Fistulae show a particularly poor response to medical treatment and are associated with a reduced quality of life. Thus, it is important to perform endoscopic examinations, even when the patient is in an asymptomatic state, and to begin therapies as early as possible.

\section{Gastric lesions}

In comparison to esophageal lesions, gastric lesions are a relatively frequent finding in $\mathrm{CD}$ patients. a bamboo-jointlike appearance (Fig. 2a, b), erosion in the antropyloric region (Fig. 3a, b) and gastric ulcer without $H$. pylori (HP) infection are observed. By 1980, Beaudin et al. reported that endoscopic findings, such as patchy redness, and small ulcers in the stomach were typical upper GIT lesions [29],
Fig. 2 The bamboo-joint-like appearance in the gastric cardiac region of a patient with Crohn's disease. These lesions are characterized by swollen longitudinal folds traversed by erosive fissures or linear furrows (a white light imaging $\mathbf{a}$; an indigo carmine chromoendoscopic imaging, b)
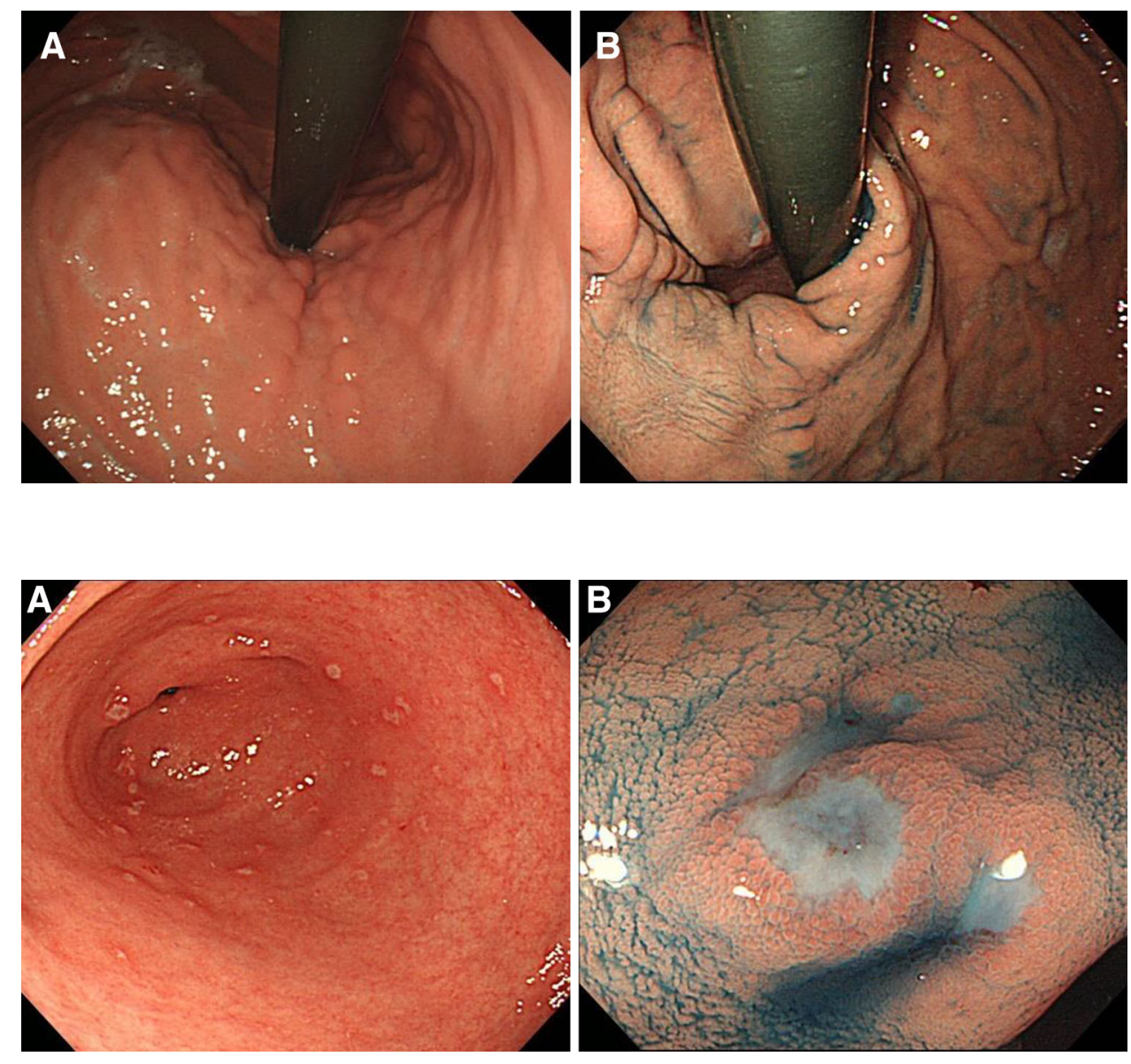

Fig. 3 Gastric erosion in the antropyloric region $(\mathbf{a}, \mathbf{b})$ of a patient with Crohn's disease. Erosion was observed in the antropyloric region (a), and indigo carmine

chromoendoscopy revealed irregularly shaped erosions (b) 
while Laufer et al. reported that the observation of multiple superficial gastric erosions on double contrast radiography of the stomach was a characteristic finding in the early stage of CD [30]. Subsequently, most reports on gastric lesions in CD patients have focused on erosive lesions in the antropyloric region, the frequency of which was reported to be $24-73 \%$ by 1990 [8, 31, 32]. In CD patients, erosion is frequently observed in the antropyloric region; the characteristics of the erosion include flat reddening, verrucous gastritis and aphthoid erosion-the morphologic features of which include circular and irregularly shaped longitudinally aligned areas of erosion. However, it is often difficult to distinguish erosive gastritis with $\mathrm{CD}$ from erosive gastritis without $\mathrm{CD}$. The combined frequency of gastric body lesions is reported to be $34-45 \%$. The gastric lesions included mucosal edema, mucosal redness and granular mucosa [11, 15], and the 'gastric lesions' were thought to contain non-specific findings related to gastritis. Thus, the sensitivity of these findings is thought to be low in CD patients. In 1997, we reported for the first time that the bamboo-joint-like appearance was found in $\mathrm{CD}$ patients [33]. These lesions are characterized by swollen longitudinal folds traversed by erosive fissures or linear furrows and were found in 54\% of CD patients. The sites of their spontaneous appearance include the lesser curvature of the cardia and the upper body. Although the bamboo-joint-like appearance can be sufficiently observed by a white light endoscope, it can be much more clearly observed by indigo carmine chromoendoscopy (Fig. 4a-d). The bamboo-jointlike appearance is frequently observed in $\mathrm{CD}$ patients. According to our previous report, the incidence of the bamboo-joint-like appearance in the stomach was $38.3 \%$ [33]. Hirokawa et al. reported that the finding was observed in 15 of $23(65.2 \%)$ CD patients [34]. Kuriyama et al. suggested that the bamboo-joint-like appearance is a characteristic stomach finding in CD patients. The detection rate of the bamboo-joint-like appearance was $44 \%$ in $\mathrm{CD}$ patients, while it was detected in $5 \%$ of ulcerative colitis patients and $0 \%$ of reflux esophagitis patients [35].
We found that the prevalence of granuloma in biopsy specimens taken from lesions with a bamboo-joint-like appearance was $45.5 \%$ (Table 2) [33]. The bamboo-jointlike appearance can rarely be detected in patients without $\mathrm{CD}$ (i.e., patients with ulcerative colitis or chronic gastritis) $[35,36]$. Although it is very rare in patients with ulcerative colitis or non-IBD, the accuracy, sensitivity and specificity of the bamboo-joint-like appearance in CD patients were reported to be $67.9,38.3$ and $97.5 \%$, respectively [36]. Thus, based on its high accuracy and specificity, the bamboo-joint-like appearance has been considered a possible biomarker for $\mathrm{CD}$. At present, the etiology of the bamboo-joint-like appearance remains unclear.

The $H P$ infection rate in $\mathrm{CD}$ patients was reported to be low [17, 37-46], Halme et al. reported that the incidence of $H P$ infection in CD patients was $9.7 \%$ and concluded that CD-associated $H P$-negative gastritis was relatively common [46]. The low $H P$ infection rate in CD patients might be due to the long-term administration of medicines, such as antibiotics and SASP [17, 40, 41, 45]. In addition, the mucosal change caused by CD may prevent the establishment of $H P$ [17, 41, 44, 45]. However, these etiologic hypotheses remain controversial. Pronai et al. compared the $H P$ infection rate between $\mathrm{CD}$ patients and chronic obstructive pulmonary disease (COPD) patients in two agematched control groups to evaluate the prevalence of $H P$ infection and the influence of antibiotics in these patients. They found that the prevalence of $H P$ infection was lower than that in the control group and that the administration of antibiotics did not affect the $H P$ infection rate [47]. Thus far, the relationship between $\mathrm{CD}$ and $H P$ remains controversial, and further study is needed to analyze the issue.

The detection rate of granuloma in biopsy specimens obtained from the stomach is reported to be $7-48.7 \%$. The detection rate showed significant differences in each report $[21,31,48]$. Hirokawa et al. reported that the prevalence of granuloma in histologic specimens obtained from lesions with the bamboo-joint-like appearance in the stomach of CD patients was $14.3 \%$ [34], which was less than the
Fig. 4 The bamboo-joint-like appearance in Crohn's disease can be much more clearly observed by indigo carmine chromoendoscopy (white light imaging $\mathbf{a}, \mathbf{b}$; indigo carmine chromoendoscopy $\mathbf{c}, \mathbf{d}$ )
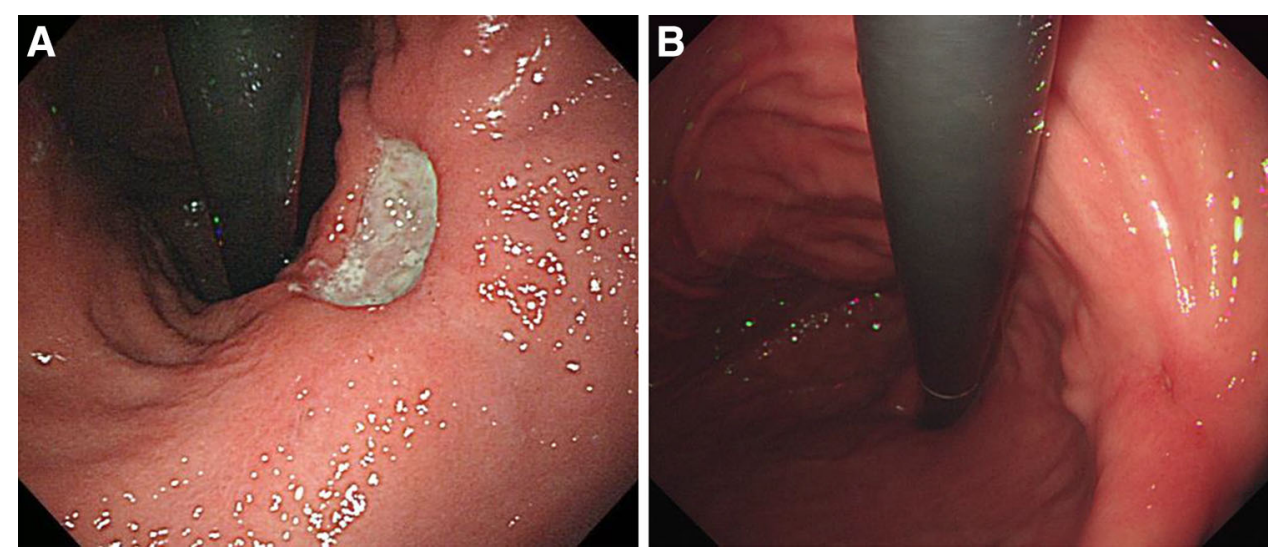
prevalence in our results (45.5\%) [33]. We took two biopsies from the lesion and made 50 serial sections for the histologic detection of granulomas. The differences in the methods of evaluation, such as the lesions that were biopsied and number of biopsies, number of pathological slices, creation of serial sections and proficiency of the pathologist $[15,33,48]$, may have also been responsible for the difference.

Although PPIs are administered as an initial treatment for the gastric lesions of CD [49], the efficacy of PPIs in the treatment of these lesions remains controversial $[50,51]$. The difference in the therapeutic endpoint, such as symptomatic improvement or mucosal healing, might be one of the reasons for this controversy. The possibility of including the lesions caused by non-IBD should also be considered. Mesalazine, corticosteroids, 6-mercaptopurine, azathioprine and anti-TNF $\alpha$ can be administered for the treatment of CD (Fig. 5a, b). These therapeutic agents are also effective for treating gastric lesions [49]. However, some cases showed resistance to these therapeutic agents, and some cases might require surgery [51]. Gastric lesions do not always reflect the disease activity. The finding of the bamboo-joint-like appearance was observed regardless of whether a patient's $C D$ was active or in remission. Thus, a bamboo-joint-like appearance could be a surrogate marker of $\mathrm{CD}$ [52].

\section{Duodenal lesions}

Various duodenal lesions are observed in CD patients, including longitudinal or irregular erosions (Fig. 6a), ulcers, aphthoid lesions, the notch-like appearance (Fig. 6b, c) and protruding lesions in the bulb and second portion of the duodenum. Erosion, ulceration and aphthoid lesions in the duodenum show similar findings to those in the stomach, and the lesions in the second portion of the duodenum show a longitudinal alignment. The notch-like appearance is caused by erosive fissures that regularly traverse folds [15]. Protruding lesions are recognized in the granular mucosa and nodular folds [8]; when they display a longitudinal arrangement, the lesions are called "Buddhist rosary-like protruding lesions" (Fig. 6d).

Regarding the frequency of duodenal lesions in $\mathrm{CD}$ patients, Cameron et al. [15] reported that the frequency was $21 \%$, while Sakuraba et al. [21] reported that the frequency was $31.9 \%$ in the duodenal bulb and $18.1 \%$ in the second portion of the duodenum. We reported that the incidence of the notch-like appearance and erosion and/or ulcers in the duodenum of CD patients was 9.9 and $32.1 \%$, respectively. These two findings were observed in 6.2 and $22.2 \%$ of non-IBD patients and 1.5 and $4.5 \%$ of UC patients, respectively [36]. Meanwhile, Sakuraba et al. suggested that the notch-like appearance in the second
Fig. 5 Gastric ulcer in the lesser curvature of the angle (a) in a patient with Crohn's disease. This lesion was PPI resistant and improved with anti-TNF $\alpha$ antibody therapy (b)
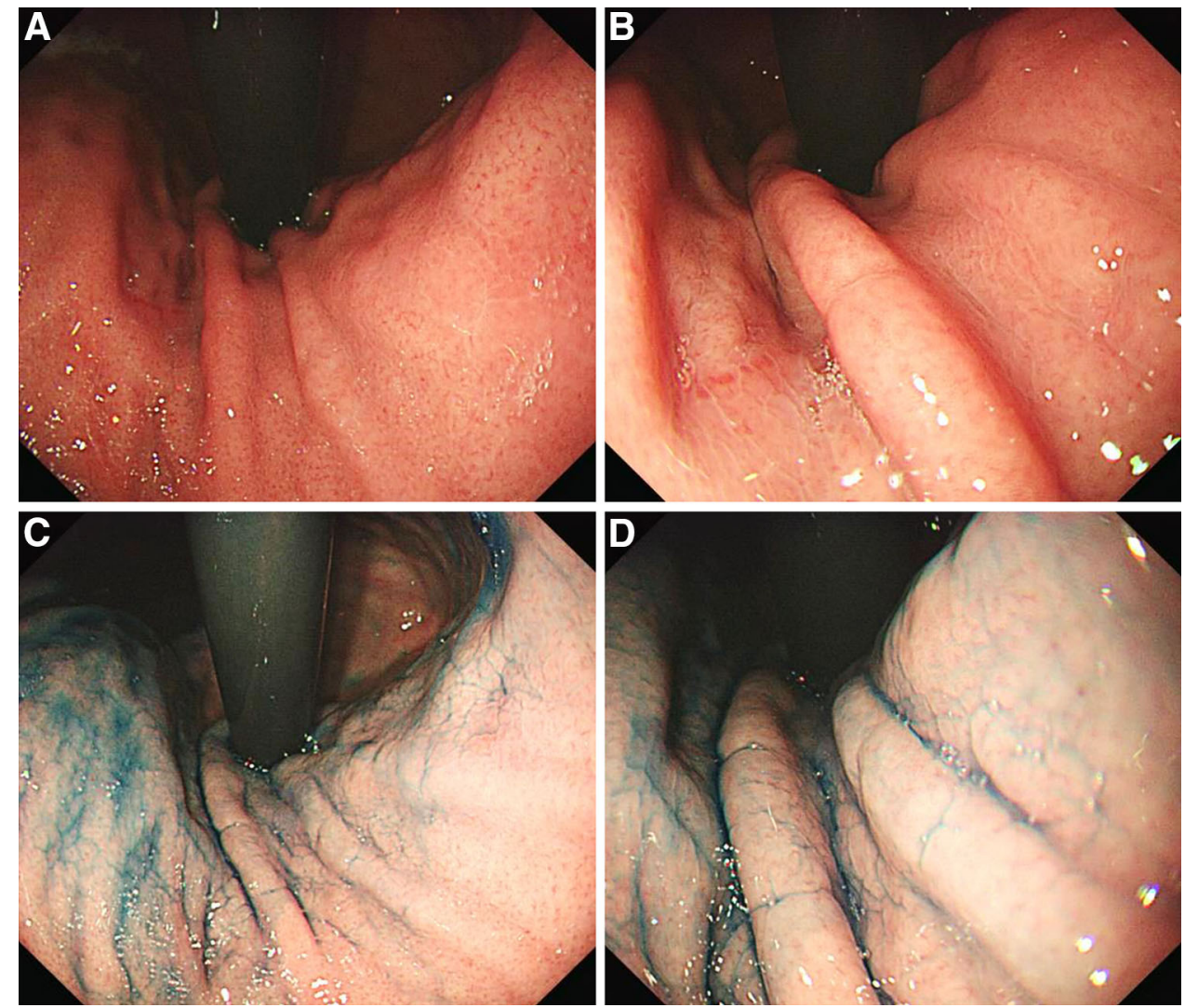
Fig. 6 Duodenal erosion in Crohn's disease shows a longitudinal tendency (a). The notch-like appearance in the second portion of the duodenum (b, c). Buddhist rosary-like protruding lesions in the superior duodenal angulus $(\mathbf{d})$
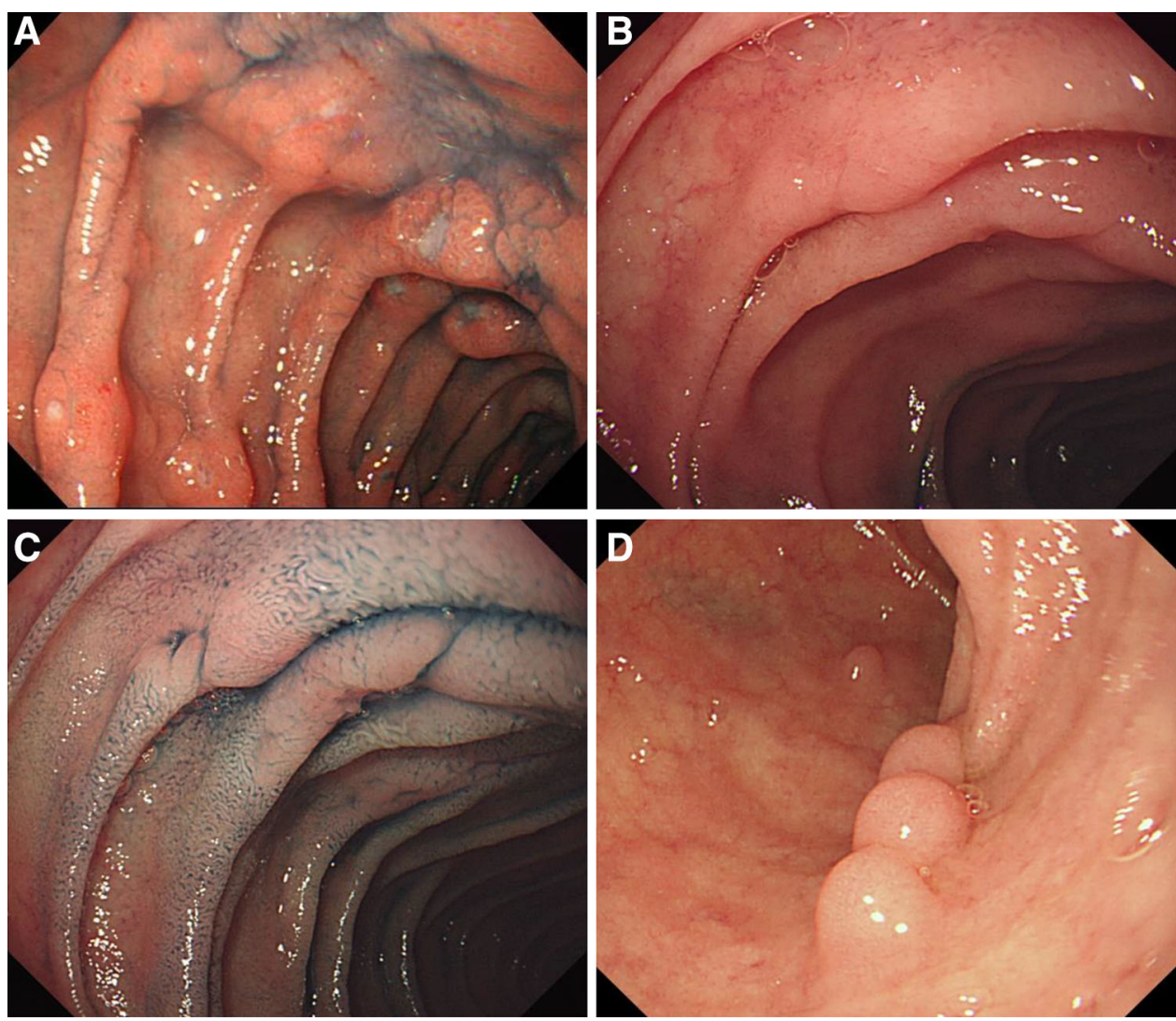

portion of the duodenum was CD-specific [21]. The frequency of duodenal lesions is relatively high, but minute lesions, such as the notch-like appearance and erosion, might be missed by white light endoscopy. Thus, the use of indigo carmine chromoendoscopy is mandatory for the detection of minute lesions. The frequency of granuloma in the duodenum is reported to be $0-49 \%$ (Table 2) [21, 31, 53]. The detection rates of granuloma in the duodenum and stomach showed significant differences in the different reports. The reasons for the discrepancy are assumed to be the same as those for the different detection rates in the stomach.

There are no specific therapeutic agents for duodenal lesions. Mesalazine, corticosteroids, 6-mercaptopurine, azathioprine and PPIs are administered for the treatment of duodenal lesions in $\mathrm{CD}$ patients (the same drugs are administered for stomach lesions) [54, 55]. Balloon dilatation is considered to be a therapeutic option for stenosis of the duodenum. Surgery is required for intractable cases with severe stenosis and fistula formation. Recently, anti-TNF $\alpha$ therapy has been reported to be useful for intractable cases [56-61]. Thus, it is crucial to perform endoscopic examination even in patients without symptoms and to screen for active inflammation in the duodenum, which enables the early initiation of treatment and which might allow the patient to avoid surgery.

\section{Conclusion}

This review focused on the upper GIT lesions in CD patients. Recent progress in the use of imaging modalities, including endoscopy, has been helpful for the diagnosis of $\mathrm{CD}$. However, many $\mathrm{CD}$ patients do not develop typical lesions; thus, some CD patients may be misdiagnosed and receive inadequate therapy. Some upper GIT lesions are considered not to be correlated with disease activity and can therefore even be detected when a patient is in remission. The bamboo-joint-like appearance in the gastric cardiac region is an important finding that can be used to identify high-risk CD patients based on the findings of esophagogastroduodenoscopy alone. Thus, it is essential for gastroenterologists to understand the characteristics of upper GIT lesions. Further studies are required to understand the diagnostic significance of upper GIT lesions.

\section{Compliance with ethical standards}

Conflict of interest The authors declare no conflict of interest in association with the present study.

Human and animal rights statement All procedures followed have been performed in accordance with the ethical standards laid down in the 1964 Declaration of Helsinki and its later amendments. 
Informed consent Written informed consent was obtained from all patients presented in this paper.

\section{References}

1. Farmer RG, Hawk WA, Turnbull RB Jr. Clinical patterns in Crohn's disease: a statistical study of 615 cases. Gastroenterology. 1975;68:627-35.

2. Tillack C, Seiderer J, Brand S, et al. Correlation of magnetic resonance enteroclysis (MRE) and wireless capsule endoscopy (CE) in the diagnosis of small bowel lesions in Crohn's disease. Inflamm Bowel Dis. 2008;14:1219-28.

3. Nikolaus S, Schreiber S. Diagnostics of inflammatory bowel disease. Gastroenterology. 2007;133:1670-89.

4. Van Assche G, Dignass A, Panes J, et al. The second European evidence-based consensus on the diagnosis and management of Crohn's disease: definitions and diagnosis. J Crohn's Colitis. 2010;4:7-27.

5. Hisabe T, Hirai F, Matsui T, et al. Evaluation of diagnostic criteria for Crohn's disease in Japan. J Gastroenterol. 2014;49:93-9.

6. Meucci G, Bortoli A, Riccioli FA, et al. Frequency and clinical evolution of indeterminate colitis:a retrospective multi-centre study in northern Italy. GSMII (Gruppo di Studio per le Malattie Infiammatorie Intestinali). Eur J Gastroenterol Hepatol. 1999;11:909-13.

7. Gottlieb C, Alpert S. Regional jejunitis. Am J Roentgenol. 1937;38:881-3.

8. Rutgeerts P, Onette E, Vantrappen G, et al. Crohn's disease of the stomach and duodenum: a clinical study with emphasis on the value of endoscopy and endoscopic biopsies. Endoscopy. 1980;12:288-94.

9. Edwards AM, Michalyshyn B, Sherbaniuk RW, et al. Regional enteritis of the duodenum: a review and report of five cases. Can Med Assoc J. 1965;93:1283-95.

10. Nugent FW, Richmond M, Park SK. Crohn's disease of the duodenum. Gut. 1977;18:115-20.

11. Schmitz-Moormann P, Malchow H, Pittner PM. Endoscopic and bioptic study of the upper gastrointestinal tract in Crohn's disease patients. Pathol Res Pract. 1985;179:377-87.

12. Tanaka M, Kimura K, Sakai H, et al. Long-term follow-up for minute gastroduodenal lesions in Crohn's disease. Gastrointest Endosc. 1986;32:206-9.

13. Mashako MN, Cezard JP, Navarro J, et al. Crohn's disease lesions in the upper gastrointestinal tract: correlation between clinical, radiological, endoscopic, and histological features in adolescents and children. J Pediatr Gastroenterol Nutr. 1989;8:442-6.

14. Lenaerts C, Roy CC, Vaillancourt M, et al. High incidence of upper gastrointestinal tract involvement in children with Crohn disease. Pediatrics. 1989;83:777-81.

15. Cameron DJ. Upper and lower gastrointestinal endoscopy in children and adolescents with Crohn's disease: a prospective study. J Gastroenterol Hepatol. 1991;6:355-8.

16. Alcantara M, Rodriguez R, Potenciano JL, et al. Endoscopic and bioptic findings in the upper gastrointestinal tract in patients with Crohn's disease. Endoscopy. 1993;25:282-6.

17. D'Inca R, Sturniolo G, Cassaro M, et al. Prevalence of upper gastrointestinal lesions and Helicobacter pylori infection in Crohn's disease. Dig Dis Sci. 1998;43:988-92.

18. Geboes K, Janssens J, Rutgeerts P, et al. Crohn's disease of the esophagus. J Clin Gastroenterol. 1986;8:31-7.

19. D'Haens G, Rutgeerts P, Geboes K, et al. The natural history of esophageal Crohn's disease. Gastrointest Endosc. 1994;40:296-300.
20. Decker GA, Loftus EV Jr, Pasha TM, et al. Crohn's disease of the esophagus: clinical features and outcomes. Inflamm Bowel Dis. 2001;7:113-9.

21. Sakuraba A, Iwao Y, Matsuoka K, et al. Endoscopic and pathologic changes of the upper gastrointestinal tract in Crohn's disease. Biomed Res Int. 2014;2014:610767. doi:10.1155/2014/ 610767.

22. Naranjo-Rodríguez A, Solórzano-Peck G, López-Rubio F, et al. Isolated oesophageal involvement of Crohn's disease. Eur J Gastroenterol Hepatol. 2003;15:1123-6.

23. De Felice KM, Katzka DA, Raffals LE. Crohn's disease of the esophagus: clinical features and treatment outcomes in the biologic era. Inflamm Bowel Dis. 2015;21:2106-13.

24. Wespi SP, Frei R, Sulz MC. A very rare cause of a relapsing paraoesophageal abscess. Case Rep Gastroenterol. 2016;10:132-8.

25. Rudolph I, Goldstein F, DiMarino AJ Jr. Crohn's disease of the esophagus: three cases and a literature review. Can J Gastroenterol. 2001;15:117-22.

26. Ohta M, Konno H, Kamiya K, et al. Crohn's disease of the esophagus, report of case. Surg Today. 2000;30:262-7

27. Dignass A, Van Assche G, Lindsay JO, et al. The second European evidence-based Consensus on the diagnosis and management of Crohn's disease: current management. J Crohns Colitis. 2010;4:28-62.

28. Lazarev M, Huang C, Bitton A, et al. Relationship between proximal Crohn's disease location and disease behavior and surgery: a cross-sectional study of the IBD Genetics Consortium. Am J Gastroenterol. 2013;108:106-12.

29. Baudin D, Da Costa LR, Prentice RS, et al. Crohn's disease of the stomach. A case report and review of the literature. Am J Dig Dis. 1978;18:623-9.

30. Laufer I, Trueman T, deSa D. Multiple superficial gastric erosion due to Crohn's disease of the stomach. Radiologic and endoscopic diagnosis. Br J Radiol. 1976;49:726-8.

31. Nugent FW, Roy MA. Duodenal Crohn's disease: an analysis of 89 cases. Am J Gaastroenterol. 1989;84:249-54.

32. Ariyama J, Wehlin L, Lindstrome CG, et al. Gastroduodenal erosions in Crohn's disease. Gastrointest Radiol. 1980;30:121-5.

33. Yokota K, Saito Y, Einami K, et al. A bamboo joint-like appearance of the gastric body and cardia: possible association with Crohn's disease. Gastrointest Endosc. 1997;46:268-72.

34. Hirokawa M, Shimizu M, Terayama K, et al. Bamboo-joint-like appearance of the stomach: a histopathological study. APMIS. 1999;107:951-6.

35. Kuriyama M, Kato J, Morimoto N, et al. Specific gastroduodenoscopic findings in Crohn's disease: comparison with findings in patients with ulcerative colitis and gastroesophageal reflux disease. Dig Liver Dis. 2008;40:468-75.

36. Fujiya M, Sakatani A, Dokoshi T, et al. A Bamboo joint-like appearance is a characteristic finding in the upper gastrointestinal tract of Crohn's disease patients: a Case-Control Study. Medicine (Baltimore). 2015;94(37):e1500.

37. Sonnenberg A, Genta RM. Low prevalence of Helicobacter pylori infection among patients with inflammatory bowel disease. Aliment Pharmacol Ther. 2012;35:469-76.

38. Xiang Z, Chen YP, Ye YF, et al. Helicobacter pylori and Crohn's disease: a retrospective single-center study from China. World $\mathrm{J}$ Gastroenterol. 2013;19:4576-81.

39. Pearce CB, Duncan HD, Timmis L, et al. Assessment of the prevalence of infection with Helicobacter pylori in patients with inflammatory bowel disease. Eur J Gastroenterol Hepatol. 2000;12:439-43.

40. El-Omar E, Penman I, Cruikshank G, et al. Low prevalence of Helicobacter pylori in inflammatory bowel disease: association with sulphasalazine. Gut. 1994;35:1385-8. 
41. Parente F, Molteni P, Bollani S, et al. Prevalence of Helicobacter pylori infection and related upper gastrointestinal lesions in patients with inflammatory bowel diseases. A cross-sectional study with matching. Scand J Gastroenterol. 1997;32:1140-6.

42. Piodi LP, Bardella M, Rocchia C, et al. Possible protective effect of 5-aminosalicylic acid on Helicobacter pylori infection in patients with inflammatory bowel disease. J Clin Gastroenterol. 2003;36:22-5.

43. Pellicano R, Bresso F, Demarchi B, et al. Prevalence of Helicobacter pylori infection in patients with inflammatory bowel disease: pilot study. Rev Esp Enferm Dig. 2010;102:675-6.

44. Triantafillidis JK, Gikas A, Apostolidiss N, et al. The low prevalence of helicobacter infection in patients with inflammatory bowel disease could be attributed to previous antibiotic treatment. Am J Gastroenterol. 2003;98:1213-4.

45. Castaño-Rodríguez N, Kaakoush NO, Lee WS, et al. Dual role of Helicobacter and Campylobacter species in IBD: a systematic review and meta-analysis. Gut. 2017;66:235-49.

46. Halme L, Karkkainen P, Rautelin H, et al. High frequency of helicobacter negative gastritis in patients with Crohn's disease. Gut. 1996;38:379-83.

47. Pronai L, Schandl L, Orosz Z, et al. Lower prevalence of Helicobacter pylori infection in patients with inflammatory bowel disease but not with chronic obstructive pulmonary diseaseantibiotic use in the history does not play a significant role. Helicobacter. 2004;9:278-83.

48. Korelitz BI, Waye JD, Kreuning J, et al. Crohn's disease in endoscopic biopsies of the gastric antrum and duodenum. Am J Gastroenterol. 1981;76:103-9.

49. Banerjee S, Peppercorn MA. Inflammatory bowel disease. Medical therapy of specific clinical presentations. Gastroenterol Clin North Am. 2002;31:185-202.

50. Miehsler W, Puspok A, Oberhuber T, et al. Impact of different therapeutic regimens on the outcome of patients with Crohn's disease of the upper gastrointestinal tract. Inflamm Bowel Dis. 2001;7:99-105.
51. Grübel P, Yoon Choi, Schneider D, et al. Severe isolated Crohn's-like disease of the gastroduodenal tract. Dig Dis Sci. 2003;48:1360-5.

52. Hashiguchi K, Takeshima F, Akazawa Y, et al. Bamboo joint-like appearance of the stomach: a stable endoscopic landmark for Crohn's disease regardless of anti-tumor necrosis factor alpha treatment. Med Sci Monit. 2014;20:1918-24.

53. Oberhuber G, Hirsch M, Stolte M. High incidence of upper gastrointestinal tract involvement in Crohn's disease. Virchows Arch. 1998;432:49-52.

54. Kimmins MH, Billingham RP. Duodenal Crohn's disease. Tech Coloproctol. 2001;5:9-12.

55. Ando T, Nobata K, Watanabe O, et al. Abnormalities in the upper gastrointestinal tract in inflammatory bowel disease. Inflammopharmacology. 2007;15:101-4.

56. Knapp AB, Mirsky FJ, Dillon EH, et al. Successful infliximab therapy for a duodenal stricture caused by Crohn's disease. Inflamm Bowel Dis. 2005;11:1123-5.

57. Odashima M, Otaka M, Jin M, et al. Successful treatment of refractory duodenal Crohn's disease with infliximab. Dig Dis Sci. 2007;52:31-2.

58. Pajares JA, Hernandez L, Menchen P, et al. Duodenopancreatic fistula complicating upper gastrointestinal Crohn's disease: successful treatment with infliximab. Am J Gastroenterol. 2009;104:1863-4.

59. Tursi A. Duodenal Crohn's disease successfully treated with adalimumab. Endoscopy. 2011;43(Suppl 2 UCTN):E22.

60. Kawachiya T, Hara J, Hirata N, et al. Successful treatment of duodenal Crohn disease with infliximab: report of 3 cases. Nihon Shokakibyo Gakkai Zasshi. 2010;107:1933-40.

61. Kim You Lim, Park Young Sook, Park Eun Kyoung, et al. Refractory duodenal Crohn's disease successfully treated with infliximab. Intestinal Res. 2014;12:66-9. 